\title{
KELAYAKAN USAHA PENANGKAPAN IKAN MENGGUNAKAN ALAT TANGKAP BUBU DASAR DI PANGKALAN PENDARATAN IKAN (PPI) KURAU KABUPATEN BANGKA TENGAH
}

\section{THE FISHING BUSINESS FEASIBILITY USING THE FISHING GEAR OF BOTTOM TRAPS (BUBU) IN FISH LANDING BASE (PPI) KURAU BANGKA TENGHA REGENCY}

\author{
Maryani $^{1 *}$, Sudirman Adibrata ${ }^{1}$, Teguh Ferdinand $^{2}$ \\ 1 Program Studi Manajemen Sumberdaya Perairan, Fakultas Pertanian Perikanan dan Biologi, \\ Universitas Bangka Belitung \\ Kampus Terpadu UBB, Gedung Teladan, Bangka, Kepulauan Bangka Belitung, 33172 Indonesia \\ 2Dinas Perikanan Kabupaten Bangka Tengah, Kepulauan Bangka Belitung \\ Komplek Perkantoran Pemerintah Kabupaten Bangka Tengah, Jalan titian puspa By Pass Koba, \\ Koba, Padang Mulia, Kabupaten Bangka Tengah, Kepulauan Bangka Belitung 33681 \\ Email: maryanimei35@gmail.com
}

\begin{abstract}
ABSTRAK
Alat tangkap bubu dasar merupakan salah satu alat tangkap yang ada di Pangkalan Pendaratan Ikan (PPI) Kurau Bangka Tengah. Usaha penangkapan ikan dengan alat tangkap bubu dasar merupakan usaha yang potensial dengan hasil tangkapan yang bernilai ekonomis tinggi yaitu berupa ikan demersal. Tujuan dari penelitian ini adalah untuk menganalisis kelayakan usaha penangkapan ikan dengan menggunakan alat tangkap bubu dasar di Pangkalan Pendaratan Ikan (PPI) Kurau Kabupaten Bangka Tengah. Metode pengumpulan data yang digunakan dalam penelitian ini adalah metode survei, wawancara dan kuesinoner. Analisis data yang digunakan yaitu analisis deskriptif kuantitatif. Hasil analisis kelayakan usaha dari usaha bubu dasar yaitu rata-rata nilai biaya investasi yang dibutuhkan yaitu Rp. 100.714.650,00, dengan rata-rata biaya total sebesar Rp. 204.343.475,00/tahun. Analisis kriteria usaha diketahui rata-rata nilai penerimaan yaitu sebesar Rp. 240.760.227,00/tahun, rata-rata pendapatan Rp. 36.416.752,00/tahun dan rata-rata PP sebesar 2,77 tahun. Analisis kiteria investasi yaitu rata-rata nilai NPV sebesar Rp. 37.510.006,00, rata-rata nilai B/C Ratio adalah 1,18 dan rata-rata nilai IRR sebesar 23,65\%. Analisis tersebut memiliki nilai NPV positif, B/C Ratio >1 dan IRR >discount rate. Hal ini menunjukkan usaha bubu dasar di Pangkalan Pendaratan Ikan (PPI) Kurau Bangka Tengah memiliki peluang yang baik dan layak untuk dijalankan.
\end{abstract}

Kata kunci : Bubu Dasar, Pangkalan Pendaratan Ikan (PPI), Kelayakan Usaha

\begin{abstract}
Bottom traps (Bubu dasar) is one of the fishing gear in Fish Landing Base (PPI) Kurau Bangka Tengah. Fishing Business with the fishing gear of bottom trap is the potential business with the high economic value caught result such as demersal fish. The aims of this research is to examine the The Fishing Business Expediency that use the bottom traps in Fish Landing Base (PPI) Kurau Bangka Tengah Regency. Data was collected using the survey method, interview and quesioners. The Data analysis that used is the descriptive quantitative analysis. The result of the The Fishing Business Feasibility using The Fishing Gear of Bottom Trap (Bubu) were the Investment cost needed was Rp. 100.714.650,00, with the total cost as much as Rp. 204.343.475,00/year. The analysis of the business criteria known that the acceptance value was Rp. 240.760.227,00/year, income was Rp. 36.416.752,00/year and PP was 2,77 year. The analysis of investmen criteria was the NPV Value was Rp. 37.510.006,00, the B/C point Ratio was 1,18 and IRR value was $23,65 \%$. Those analysis had the positive NVP Point, B/C Ratio Ratio>1 and IRR >discount rate. The result showed that the bottom traps fishing business in fish landing base (PPI) Kurau Bangka Tengah has the good potential/ opportunity and worth to operate.
\end{abstract}

Keywords : Bottom traps (Bubu dasar), Fish Landing Base (PPI), Business Feasibility 


\section{PENDAHULUAN}

Provinsi Kepulauan Bangka Belitung merupakan salah satu provinsi kepulauan terletak pada 050' - 4²10'LS dan 10450' 109³0'BT dengan batas -batas wilayah: Selat Bangka (sebelah Barat), Selat Karimata (sebelah Timur), Laut Natuna (sebelah Utara) dan Laut Jawa (sebelah Selatan). Provinsi Kepulauan Bangka Belitung memiliki produksi kelautan dan perikanan yang besar seperti perikanan tangkap (BPS Bangka Tengah, 2018). Produksi perikanan tangkap provinsi kepulauan bangka belitung yaitu sebesar 203.284.4 ton. Salah satu kabupaten yang memiliki potensi perikanan tangkap di provinsi Kepulauan Bangka Belitung yaitu Kabupaten Bangka Tengah dengan nilai tangkapan sebesar 25.068.94 ton. (DKP Bangka Tengah, 2018). Potensi perikanan tangkap di Kabupaten Bangka Tengah salah satunya terdapat di desa Kurau.

Desa Kurau merupakan salah satu desa yang terletak di kabupaten bangka tengah yang memiliki mayoritas mata pencaharian yaitu nelayan. Di desa kurau terdapat pangkalan pendaratan ikan yang digunakan untuk kegiatan perikanan. Terdapat beberapa alat tangkap di Pangkalan Pendaratan Ikan (PPI) Kurau Kabupaten Bangka Tengah yaitu pukat udang, payang, jaring insang hanyut, jaring insang tetap, jaring angkat, pancing ulur, bubu, pancing tonda, dan bagan (Profil UPT PPI/TPI Kurau, 2018).

Bubu merupakan salah satu alat tangkap yang terdapat di Pangkalan Pendaratan Ikan (PPI) Kurau Kabupaten Bangka Tengah. Jenis bubu yang terdapat di Pangkalan Pendaratan Ikan (PPI) Kurau yaitu bubu dasar. Bubu dasar adalah salah satu alat penangkapan yang dikategorikan sebagai alat tangkap perangkap dan merupakan alat tangkap yang sifatnya pasif atau menetap didasar perairan yang bertujuan menangkap ikan-ikan demersal (Malik, 2013).

Usaha penangkapan ikan dengan alat tangkap bubu dasar merupakan usaha yang potensial dengan hasil tangkapan yang bernilai ekonomis tinggi yaitu berupa ikan demersal. Akan tetapi pada usaha penangkapan terdapat permasalahan yaitu hasil tangkapan yang tidak bisa diperkirakan hasilnya, sehingga akan mempengaruhi pendapatan nelayan. Hasil tangkapan yang berfluktuasi mengakibatkan nelayan harus bisa mengatur penerimaan dengan baik agar modal yang dikeluarkan berbanding dengan pemasukan yang didapat. Untuk itu diperlukan informasi mengenai modal, biaya - biaya yang dikeluarkan dalam proses produksi dari usaha penangkapan bubu dasar di Pangkalan Pendaratan Ikan (PPI) Kurau Kabupaten Bangka Tengah agar dapat menciptakan usaha yang berkelanjutan (Hartono, 2018).

Usaha penangkapan ikan dengan bubu dasar ini belum diketahui apakah memberikan keuntungan secara ekonomi bagi nelayan bubu dasar di Pangkalan Pendaratan Ikan (PPI) Kurau Kabupaten Bangka Tengah. Maka dari hal tersebut diperlukan penelitian ini untuk melihat Kelayakan Usaha Penangkapan Ikan Menggunakan Alat Tangkap Bubu Dasar di Pangkalan Pendaratan Ikan (PPI) Kurau Kabupaten Bangka Tengah.

\section{METODE PENELITIAN}

Penelitian ini akan dilakukan pada bulan maret 2020 di Pangkalan Pendaratan Ikan (PPI) Kurau Kabupaten Bangka Tengah. Pengambilan sampel dilakukan pada nelayan bubu dasar yang berada di Pangkalan Pendaratan Ikan (PPI) Kurau Kabupaten Bangka Tengah. Metode pengumpulan data yang digunakan dalam penelitian ini yaitu metode survei, metode wawancara dan metode sebaran angket (kuesioner). Data yang dibutuhkan yaitu data primer dan data sekunder. Data primer diperoleh melalui wawancara dan kuesioner yang meliputi data biaya investasi, biaya tetap, biaya tidak tetap dan penerimaan (hasil tangkapan).

Biaya investasi terdiri dari investasi kapal, alat tangkap bubu dasar, mesin, dan alat navigasi. Biaya tetap terdiri dari biaya perawatan dan biaya penyusutan unit penangkapan bubu dasar. Biaya tidak tetap terdiri dari biaya bahan bakar, es dan pembekalan makanan. Data sekunder yang diperoleh dari data Kantor Dinas Kelautan Perikanan Bangka Tengah dan dari kantor Pangkalan Pendaratan Ikan Kurau meliputi data jumlah nelayan, data jumlah kapal, dan produksi hasil tangkapan bagan tancap. Metode pengambilan sampel yang digunakan dalam penelitian ini adalah metode sensus. Metode sensus adalah metode pengambilan sampel yang dilakukan dengan cara mengambil semua anggota populasi sebagai sampel (Putri \& Nyoman, 2016). Jumlah sampel pada penelitian ini sebanyak 22 sampel (Data kapal PPI).

\section{Analisis Data}

Analisis yang digunakan dalam penelitian ini adalah analisis deskriptif 
kuantitatif. Menurut Sugiyono (2012) penelitian deskriprif kuntitatif yaitu, penelitian yang dilakukan untuk mengetahui nilai variabel mandiri, baik satu variabel atau lebih tanpa membuat perbandingan, atau menghubungkan dengan variabel lain. Metode analisis kuantitatif yang digunakan yaitu dengan mengkaji aspek kelayakan usaha melalui pendekatan aspek finansial dengan menggunakan analisis kriteria usaha yang meliputi, Penerimaan, Pendapatan dan Payback Period (PP). Analisis kriteria Investasi meliputi Net Present Value (NPV), Net Benefit Cost Ratio (Net B/C), Internal Rate of Return (IRR). Data kuantitatif diolah menggunakan kalkulator dan komputer dengan Microsoft excel 2007.

\section{Analisis Kelayakan Usaha}

\section{Analisis Kriteria Usaha Penerimaan}

Penerimaan merupakan perkalian antara produksi yang diperoleh atau hasil tangkapan dengan harga jual. Rumus perhitungan penerimaan menurut Bangun (2010) adalah sebagai berikut :

$$
\mathrm{TR}=\mathrm{P} \times \mathrm{Q}
$$

Keterangan : TR = Total penerimaan; $\mathrm{P}=$ Harga Jual $; \mathrm{Q}=$ Hasil Tangkapan

\section{Pendapatan Usaha}

Analisis pendapatan usaha bertujuan untuk mengetahui besarnya keuntungan yang diperoleh dari suatu kegiatan usaha yang dilakukan. Rumus perhitungan keuntungan menurut Tibrani \& Sofyani (2010) sebagai berikut:

$$
\Pi=\mathrm{TR}-\mathrm{TC}
$$

Keterangan : $\Pi=$ Keuntungan; $T R=$ Total penerimaan; $\mathrm{TC}=$ Total biaya

Dengan kriteria : $\mathrm{TR}>\mathrm{TC}=$ kegiatan usaha mendapatkan keuntungan, $\mathrm{TR}<\mathrm{TC}=$ kegiatan usaha tidak mendapatkan keuntungan, Jika $\mathrm{TR}=\mathrm{TC}=$ kegiatan usaha berada pada titik impas atau usaha tidak mendapatkan untung atau rugi.

\section{Payback Period (PP)}

Payback Period adalah suatu periode yang diperlukan untuk menutup kembali pengeluaran investasi (initial cash investment) dengan menggunakan aliran kas.
Rumus Payback Period menurut Noer (2011) adalah sebagai berikut:

$$
\mathrm{PP}=\frac{\text { Nilai invest } \mathrm{N}}{\text { Keuntungan }} \times 1 \text { tahun }
$$

Kriteria : Nilai Payback Period kurang dari 3 tahun pengembalian modal usaha dikategorikan cepat; Nilai Payback Period 3-5 tahun kategori pengembalian sedang; Nilai Payback Period lebih dari 5 tahun dikategorikan pengembalian lambat.

\section{Analisis Kriteria Investasi}

\section{Net Present Value (NPV)}

NPV yaitu selisih antara Present Value dari investasi dan nilai sekarang dari penerimaan-penerimaan kas bersih (arus kas operasional maupun arus kas terminal) di masa yang akan datang. Untuk menghitung nilai sekarang perlu ditentukan tingkat bunga yang relevan. Rumus perhitungan Net Present Value menurut Tangke (2011) adalah sebagai berikut:

$$
N P V=\sum_{t=1}^{n} \frac{(\mathrm{Bt}-\mathrm{Ct})}{(1+t)^{1}}
$$

Keterangan: $\mathrm{Bt}=$ Keuntungan dari suatu usaha pada tahun ke- $t$; $\mathrm{Ct}=$ Biaya dari usaha pada tahun ke- $t ; \mathrm{i}=$ tingkat suku bunga yang berlaku; $\mathrm{t}=$ tahun ke-; $\mathrm{n}=$ Umur usaha

dimana : NPV $>1=$ maka usaha tersebut layak; $\mathrm{NPV}=0=$ maka usaha tersebut dapat layak; $\mathrm{NPV}<1=$ maka usaha tersebut tidak layak

\section{Benefit Cost Ratio (B/C Ratio)}

$B / C$ Ratio dimaksudkan untuk mengetahui besarnya nilai perbandingan penerimaan dan biaya produksi yang digunakan. Rumus perhitungan B/C Ratio menurut Tibrani dan Sofyani (2010) adalah sebagai berikut:

$$
\mathrm{B} / \mathrm{C} \text { Ratio }=\frac{\text { Pendapatan }}{\text { Total biaya }}
$$

Kriteria yang digunakan adalah: $B / C$ ratio $>1$ $=$ berarti usaha menghasilkan keuntungan sehingga layak untuk dijalankan; $B / C$ ratio $=$ 1 = berarti usaha tidak untung dan tidak rugi (impas); $B / C$ ratio $<1=$ berarti usaha mengalami kerugian sehingga tidak layak untuk dijalankan. 


\section{Internal Rate of Return (IRR)}

IRR adalah merupakan tingkat bunga yang akan menjadikan jumlah nilai sekarang dari produk sama dengan jumlah nilai sekarang dari pengeluaran modal. Rumus perhitungan Internal Rate of Return menurut Tangke (2011) adalah sebagai berikut:

$$
I R R=i^{\prime}+\frac{N P V^{\prime}}{N P V^{\prime}-N P V^{\prime \prime}}\left(i^{\prime \prime}-i^{\prime}\right)
$$

Keterangan: $\mathrm{i}^{\prime}=$ tingkat bunga pada NPV positif; $i^{\prime \prime}=$ tingkat bunga pada NPV negative; $\mathrm{NPV}^{\prime}=$ hasil NPV positif; $\mathrm{NPV}^{\prime \prime}=$ hasil NPV negative;

Usaha dikatakan layak jika, IRR > discount rate, sedangkan usaha dikatakan tidak layak jika IRR < discount rate.

Berdasarkan hasil penelitian di dapatkan karakteristik responden berdasarkan umur dan lama usaha. Umur seseorang dapat menggambarkan seberapa besar efektifitas kerja yang dapat mereka lakukan. Berdasarkan Tabel 2, dapat diketahui bahwa responden terbanyak adalah responden yang memiliki rentang usia 39-43 tahun yaitu sebanyak 7 orang. Rentang usia tersebut berada pada rentang usia tenaga kerja yang produktif. Menurut Imron (2017) Usia Produktif yaitu 15-64 tahun. Kemudian diikuti responden yang berusia diatas 48 tahun sebanyak 5 orang, kemudian responden yang berusia 24-28 tahun sebanyak 4 orang, kemudian 29-33 tahun sebanyak 2 orang, 34-38 tahun sebanyak 2 orang dan 44-48 tahun sebanyak 2 orang. Berdasarkan Tabel 3, dapat dilihat bahwa pengalaman usaha nelayan bubu dasar di PPI Kurau selama 5-9 tahun merupakan rentang pengalaman usaha yang paling banyak. Sedangkan untuk pengalaman usaha lebih dari 19 tahun merupakan rentang usaha yang paling sedikit.

Tabel 2.Karakteristik responden berdasarkan umur

\begin{tabular}{ccc}
\hline No & Rentang usia & Jumlah \\
\hline 1 & $24-28$ tahun & 4 \\
2 & $29-33$ tahun & 2 \\
3 & $34-38$ tahun & 2 \\
4 & $39-43$ tahun & 7 \\
5 & $44-48$ tahun & 2 \\
6 & $>48$ tahun & 5 \\
& Total & 22 \\
\hline
\end{tabular}

Tabel 3. lama usaha

\begin{tabular}{rrr}
\hline No & Lama Usaha & Jumlah \\
\hline 1 & $5-9$ tahun & 11 \\
2 & $10-14$ tahun & 6 \\
3 & $15-19$ tahun & 3 \\
4 & $>19$ tahun & 2 \\
& Total & 22 \\
\hline
\end{tabular}

\section{Aspek Teknis Bubu Dasar}

Berdasarkan hasil penelitian yang telah dilakukan didapatkan kontruksi bubu dasar yang terdapat di Pangkalan Pendaratan Ikan (PPI) Kurau Bangka Tengah dapat dilihat pada Tabel 4.

Tabel 4. Kontruksi Bubu Dasar

\begin{tabular}{ccc}
\hline No & Kontruksi & Bahan \\
\hline 1 & Kerangka & Kayu/rotan \\
2 & Badan & Kawat \\
3 & Mulut & Kawat \\
4 & Pemberat & Batu/semen \\
5 & Pelampung & PVC \\
6 & Jangkar & Batu \\
7 & Tali penghubung antara & PE \\
& bubu, pelampung dan & \\
& jangkar & \\
\hline
\end{tabular}

Kerangka berfungsi memberi bentuk pada bubu. Kerangka bubu dasar yang terdapat di PPI Kurau Kabupaten Bangka Tengah memiliki ukuran yang bervariasi yang memiliki bentuk segi lima dan terbuat dari dua bahan, yaitu dari kayu dan rotan. Menurut (Yohanes et al., 2013), kerangka dibuat dari material yang kuat dan dapat mempertahankan bentuk bubu ketika dioperasikan. Badan bubu dasar di PPI Kurau Kabupaten Bangka Tengah memiliki bentuk segi lima terbuat dari bahan kawat. Bagian ini dilengkapi dengan pemberat dari batu atau semen yang berfungsi untuk menenggelamkan bubu ke dasar perairan yang terletak pada tiap sudut bubu. Menurut (Martasuganda, 2008), penggunaan bahan kawat dalam pembuatan bubu karena kawat lebih tahan lama dibandingkan dengan bahan lainnya. Berdasarkan penelitian yang telah dilakukan didapatkan bentuk mulut bubu dasar yang terdapat di PPI Kurau yaitu berbentuk leher kuda. Bahan yang digunakan untuk bagian mulut ini yaitu menggunakan kawat dan ukuran bagian mulut ini bervariasi. Posisi mulut bubu menjorok ke dalam badan. Semakin ke dalam diameter lubangnya 
semakin mengecil dan bagian mulut bagian dalam melengkung ke bawah. Lengkungan ini berfungsi agar ikan yang masuk sulit untuk meloloskan diri keluar (Lukman, 2013). Pemberat yang digunakan pada alat tangkap bubu dasar di PPI Kurau yaitu terbuat dari batu atau semen.

Pemberat berfungsi untuk menahan alat tangkap bubu dasar agar tidak terbawa arus dan gelombang ( Kalsum, 2014). Berat pemberat yang digunakan pada bubu dasar di PPI Kurau yaitu berkisar antara $2 \mathrm{~kg}$ sampai $4 \mathrm{~kg}$. Pelampung adalah barang yang ringan terapung (yang dapat menahan supaya tidak tenggelam). Pelampung yang digunakan pada bubu dasar di PPI Kurau terbuat dari bahan PVC (polyvinylchloride). Jangkar yang digunakan pada alat tangkap bubu dasar di PPI Kurau adalah batu. Jangkar ini digunakan pada ujung tali penghubung yang digunakan untuk mempermudah dalam pengangkatan bubu. Tali penghubung antara bubu dasar dengan jangkar yang digunakan di PPI Kurau yaitu terbuat dari bahan PE (polyethylene). Pada tali penghubung ini, terdapat pelampung dibagian tengah tali antara bagian bubu dengan bagian jangkar yang berfungsi memberikan daya apung pada bagian tengah tali penghubung tersebut. Pemberian pelampung pada bagian tengah tali penghubung tersebut bertujuan untuk memudahkan pada proses pengangkatan bubu.

Metode pengoperasian bubu dasar terdiri dari beberapa tahap yaitu tahap pemasangan, perendaman dan pengangkatan. Sebelum nelayan pengoperasian bubu dasar, nelayan akan melakukan persiapan, yaitu persiapan bahan bakar, es dan perbekalan makanan. Persiapan bahan-bahan tersebut dilakukan sehari sebelum nelayan berangkat melaut. Nelayan akan berangkat dari pangkalan menuju lokasi penangkapan pada pagi hari dan tiba pada siang atau sore hari. Tahap pemasangan diwali dengan mencatat titik koordinat dengan menggunakan GPS (Global Positioning System). Setelah dilakukan pencatatan titik koordinat, kemudian langsung dilakukan penurunan bubu ke dalam perairan dengan cara menurunkan bubu terlebih dahulu dan kemudian bagian ujung tali yang ada pemberat (jangkar). Karena kedua bagian dari ujung tali sama-sama berat dan bagian tengah dari tali tersebut terdapat pelampung, maka bagian tengah tali tersebut akan mengapung tetapi tidak mengapung sampai ke permukaan. Perendaman bubu dasar yang dilakukan oleh nelayan di Pangkalan
Pendaratan Ikan (PPI) Kurau Kabupaten Bangka Tengah berkisar antara 3 sampai 7 hari. Menurut (Martasuganda dalam Perdana 2016), lama perendaman bubu di perairan yaitu berbeda-beda. Ada yang hanya direndam beberapa jam, ada yang direndam satu malam, ada juga yang direndam sampai 3 hari 3 malam dan bahkan ada yang direndam sampai 7 hari 7 malam. Pengangkatan bubu dasar yang dilakukan nelayan di PPI Kurau Kabupaten Bangka Tengah menggunakan alat bantu yaitu alat penarik bubu dasar (pemarit) dan mesin penarik. Alat bantu pengoperasian alat tangkap bubu dasar di PPI Kurau. Nelayan akan menuju ke lokasi penangkapan yang sudah direkam titik koordinatnya menggunakan GPS pada waktu proses pemasangan. Proses pengangkatan bubu dasar dilakukan dengan cara melemparkan pemarit hingga mengenai bagian tali yang mengapung, kemudian tali yang terkena pemarit tersebut ditarik dan diletakan pada mesin penarik. Selanjutnya mesin penarik akan menarik tali tersebut hingga bubu sampai ke permukaan dan kemudian di naikan ke atas kapal.

\section{Hasil Tangkapan}

Jenis ikan hasil tangkapan yang didapatkan pada usaha bubu dasar di PPI Kurau yaitu Ikan Kerapu Sunu, Ikan Ekor Kuning, Ikan Kakap Merah, Ikan Jebung, Ikan Gaji , Ikan Kakak Tua, Ikan Tambak Pasir. Adapun jenis ikan hasil tangkapan utama yaitu ikan kerapu sunu dan ikan ekor kuning. Beberapa jenis ikan hasil tangkapan bubu dasar di PPI Kurau juga ditemukan oleh nelayan bubu di Kabupaten Bangka selatan, hal ini dikarenakan daerah tangkapan nelayan bubu dasar di kabupaten bangka selatan sama dengan daerah tangkapan nelayan bubu dasar di desa kurau. Hal ini sesuai dengan penelitian Noer (2011) yang menemukan hasil tangkapan bubu dasar yaitu ikan kerapu, kerapu sunu, kakap merah, ekor kuning, swanggi, tambangan dan baronang.

\section{Analisis kelayakan usaha}

Berdasarkan penelitian yang telah dilakukan, didapatkan nilai rata-rata dari analisis kelayakan usaha pada usaha bubu dasar di PPI dapat dilihat pada Tabel 5.

\section{Biaya}

Biaya merupakan sejumlah uang yang dikeluarkan (atau dapat berbentuk hutang) 
untuk kegiatan operasi perusahaan dalam rangka menghasilkan barang - barang atau jasa -jasa.

Investasi pada usaha perikanan tangkap adalah modal awal yang harus dimiliki ketika akan melakukan suatu usaha perikanan tangkap. Biaya Investasi adalah pengeluaranpengeluaran yang dilakukan pada saat ini untuk memperoleh hasil yang diharapkan di masa yang akan datang (Gigentika et al., 2013). Berdasarkan Tabel 5, didapatkan nilai biaya investasi pada usaha bubu dasar di PPI Kurau Bangka Tengah sebesar Rp. 100.714.650,00. Investasi terbesar pada usaha penangkapan bubu dasar adalah kapal. Salah satu penyebab besarnya nilai investasi kapal adalah pengadaan kapal dilakukan dengan membeli kapal jadi yang didatangkan dari luar daerah (Wijaya et al., 2012). Berdasarkan Tabel 5, didapatkan nilai biaya tetap yang harus dikeluarkan pada usaha perikanan bubu dasar adalah Rp. 45.232.709,00/tahun. Biaya tetap pada usaha perikanan bubu dasar meliputi biaya perawatan dan biaya penyusutan. Biaya tetap merupakan biaya yang wajib diperhitungkan oleh pelaku usaha untuk menjalankan usahanya (Prasetyo, 2016).

Biaya tidak tetap adalah biaya yang jumlah totalnya berubah sebanding dengan perubahan volume kegiatan (Asnidar \& Asrida, 2017). Biaya tidak tetap juga diartikan sebagai biaya yang dikeluarkan oleh pelaku usaha pada setiap trip (Prasetyo et al., 2016). Biaya tidak tetap yang dikeluarkan pada usaha perikanan bubu dasar yaitu sebesar Rp. 159.110.766,00/tahun. Biaya tidak tetap pada usaha perikanan bubu dasar yaitu meliputi biaya bahan bakar minyak (bbm), es, perbekalan dan gaji anak buah kapal. Biaya total adalah penjumlahan dari seluruh biaya yang ada, yaitu biaya tetap dan biaya tidak tetap (Prasetyo et al.

Tabel 5.Analisis kelayakan usaha bubu dasar

\begin{tabular}{clc}
\hline No & \multicolumn{1}{c}{ Uraian } & Nilai \\
\hline & Biaya & \\
1 & Investasi (Rp.) & 100.714 .650 \\
2 & Biaya Tetap (Rp.) & 45.232 .709 \\
& Biaya tidak tetap & \\
3 & (Rp.) & 159.110 .766 \\
4 & Biaya Total (Rp.) & 204.343 .475 \\
& Kriteria Usaha & \\
5 & Penerimaan (Rp.) & 240.760 .227 \\
6 & Pendapatan (Rp.) & 36.416 .752 \\
7 & PP (Tahun) & 2,77 \\
& Kriteria Investasi & 37.510 .006 \\
8 & NPV (Rp) & 1,18 \\
9 & B/C & 23,65 \\
10 & IRR (\%)
\end{tabular}

2016). Nilai biaya total pada usaha bubu dasar adalah Rp. 204.343.475,00/tahun. Biaya terbesar yang dikeluarkan dalam usaha penangkapan ikan menggunakan alat tangkap bubu dasar berasal dari biaya tidak tetap yaitu sebesar 159.110.766,00/tahun.

\section{Analisis Kriteria Usaha}

\section{Penerimaan}

Penerimaan didapat dari hasil penjualan produksi ikan yang dipengaruhi oleh besarnya jumlah ikan yang diperoleh dan harga yang terbentuk pada saat didaratkan. Nilai penerimaan nelayan selama satu tahun adalah sebesar Rp. 240.760.227,00/tahun. Dalam usaha penangkapan ikan, penerimaan sangat tidak menentu tergantung dari jumlah ikan yang didapatkan. Hal ini dipengaruhi oleh musim penangkapan ikan dan kondisi perairan daerah penangkapan (Ningsih et al., 2013).

\section{Pendapatan}

Berdasarkan Tabel 5, nilai pendapatan pada usaha penangkapan ikan dengan menggunakan bubu dasar sebesar Rp. 36.416.752,00/tahun. Jumlah pendapatan sangat tergantung pada jumlah penerimaan dan besarnya biaya yang dikeluarkan dalam proses produksi. Menetapkan besarnya pendapatan yang diterima oleh nelayan bubu dasar adalah dengan menghitung selisih antara penerimaan dengan jumlah pengeluaran atau biaya yang berupa biaya tetap maupun biaya variabel (Suhdi, 2015).

\section{Payback Period (PP)}

Payback Period dalam studi kelayakan usaha berfungsi untuk mengetahui berapa lama usaha yang akan dilakukan dapat mengembalikan investasi. Tingkat pengembalian modal suatu usaha dikategorikan cepat jika nilai PP $<3$ tahun, tingkat pengembalian modal dikategorikan sedang jika nilai PP 3-5 tahun dan dikatakan dalam kategori tingkat pengembalian lambat jika nilai PP > 5 tahun (Suhdi, 2015). Berdasarkan Tabel 5, nilai payback period pada usaha penangkapan ikan dengan menggunakan bubu dasar sebesar 2,77 tahun. Nilai tersebut menunjukan bahwa usaha penangkapan ikan dengan menggunakan bubu dasar membutuhkan waktu 2 tahun 9 bulan 2 hari untuk balik modal, maka usaha tersebut dapat dikategorikan pengembalian modal cepat karena kurang dari 3 tahun. 


\section{Analisis Kriteria Investasi}

\section{Net Present Value (NPV)}

Net Present Value (NPV) merupakan selisih antara present value kas bersih dengan present value investasi selama umur investasi. Dalam metode ini discount rate faktor yang digunakan adalah sebesar 9,95\% sesuai tingkat suku bunga bank rata-rata yang berlaku saat ini. Berdasarkan Tabel 3, nilai NPV pada usaha penangkapan ikan dengan menggunakan bubu dasar sebesar Rp. 37.510.006,00. Nilai NPV pada usaha penangkapan ikan dengan menggunakan bubu dasar bernilai positif, hal tersebut menunjukkan bahwa usaha tersebut layak untuk dilanjutkan. Menurut Ningsih (2013), semakin tinggi NPV suatu usaha, maka semakin baik pula usaha tersebut dan usaha yang dapat menaikkan keuntungan yaitu yang mempunyai NPV lebih besar.

\section{Benefit Cost Ratio (B/C)}

Benefit Cost Ratio (B/C) diperoleh dari hasil perhitungan antara jumlah sekarang dari pendapatan dan nilai sekarang dari biaya, sepanjang usaha tersebut berjalan. Apabila didapat nilai B/C Ratio lebih besar dari pada satu maka usaha tersebut layak untuk diteruskan. dan jika lebih kecil dari pada satu maka usaha tersebut tidak layak diteruskan. Berdasarkan Tabel 3, nilai B/C pada usaha penangkapan ikan dengan menggunakan bubu dasar sebesar 1,18. Berdasarkan nilai $B / C$ usaha perikanan tangkap bubu dasar layak untuk diteruskan karena nilai $\mathrm{B} / \mathrm{C}$ lebih besar dari satu.

\section{Internal Rate of Return (IRR)}

$\begin{array}{llrr}\begin{array}{l}\text { Internal Rate of } \\ \text { merupakan }\end{array} \text { tingkat } & \begin{array}{c}\text { Return } \\ \text { bunga }\end{array} & \begin{array}{r}\text { (IRR) } \\ \text { yang }\end{array} \\ \text { menggambarkan bahwa } & \text { antar } & \text { benefit }\end{array}$ (keuntungan) yang telah di present value kan dan cost (pengeluaran) yang telah di present value kan sama dengan nol. Kriteria investasi IRR ini memberikan pedoman bahwa usaha akan dijalankan apabila IRR > discount rate. Begitu pula sebaliknya, jika diperoleh IRR < discount rate, maka usaha sebaiknya tidak dijalankan (Ningsih, 2013). Berdasarkan Tabel 3, nilai IRR pada usaha penangkapan ikan dengan menggunakan bubu dasar sebesar 23,65\%. Nilai IRR tersebut lebih besar dari discount factor yaitu 9,95\% jadi dapat dikatakan bahwa usaha perikanan ini layak untuk diteruskan.

\section{KESIMPULAN}

Berdasarkan analsiis kriteria kelayakan usaha dan kriteria investasi yang telah dilakukan, maka analisis kelayakan usaha penangkapan ikan menggunakan alat tangkap bubu dasar di Pangkalan pendaran ikan (PPI) Kurau Kabupaten Bangka Tengah memenuhi kriteria layak untuk dilanjutkan.

\section{REFERENSI}

Asnidar., \& Asrida. 2017. Analisis Kelayakan Usaha Home Industry Kerupuk Opak Di Desa Paloh Meunasah Dayah Kecamatan Muara Satu Kabupaten Aceh Utara. Jurnal Sains Pertanian, 1(1):3947

[BPS] Badan Pusat Statistik Kabupaten Bangka Tengah. Kabupaten Bangka Tengah dalam Angka 2018. BPS Kabupaten Bangka Tengah. SSN: 23386568.

Gigentika, S., Wisodo, S.H., \& Mustaruddin. 2013. Kelayakan Finansial Usaha Perikanan Pancing Tonda di PPP Labuhan Lombok Kabupaten Lombok Timur. Buletin PSP. 21(2):137-148

Hartono, F.I. 2018. Analisis Aspek Teknis Dan Finansial Perikanan Bagan Rambo Di Pusat Pelelangan Ikan Desa Wewangriu Kecamatan Malili Kabupaten Luwu Timur. Fakultas Ilmu Kelautan Dan Perikanan. [Skripsi]. Universitas Hasanuddin

Imron 2017. Memanfaatkan Usia Produktif Dengan Usaha Kreatif Industri Pembuatan Kaos Pada Remaja Di Gresik. Paradigma. Vol. 05, No. 03

Martasuganda. S. 2008. Bubu (Traps) : Serial Teknologi Penangkapan Ikan Berwawasan Lingkungan. Institut Pertanian Bogor. IPB Press. Bogor

Malik, R.F. 2013. Kajian Beberapa Disain Alat Tangkap Bubu Dasar Diperairan Kepulauan Ternate Provinsi Maluku Utara. Jurnal IImiah agribisnis dan Perikanan, 6(1):52-57

Ningsih, S.R., Mudzakir, K.A., \& Rosyid, A. 2013. Analisis Kelayakan Finansial Usaha Perikanan Payang Jabur (Boat Seine) Di Pelabuhan Perikanan Pantai Asemdoyong Kabupaten Pemalang. Journal of Fisheries Resources Utilization Management and Technology. 2:223-232

Noer, J. 2011. Perikanan Bubu Dasar Di Kabupaten Bangka Selatan Provinsi Kepulauan Bangka Belitung Perikanan Bubu Dasar di Kabupaten Bangka 
Selatan Provinsi Kepulauan Bangka Belitung [Tesis],Institut Pertanian Bogor Perdana, I.T.M., Boesono, H., \& Sardiyatmo. 2016. Pengaruh Umpan Dan Lama Perendaman Alat Tangkap Jebak (Bubu Lipat) Terhadap Hasil Tangkapan Rajungan (Portunus Pelagicus) di Desa Semat, Jepara. Journal of Fisheries Resources Utilization Management And Technology. 5(1):1-8

Prasetyo, B.A., Setiyanto, I., \& Hapsari, D.T. 2016. Analisis Usaha Perikanan Tangkap kapal Purse Seine berpendingin Freezer dibandingkan Dengan Es Di Pelabuhan Perikanan Pantai (PPP) Bajomulyo, Juwana, Kabupaten Pati. Journal of Fisheries Resources Utilization Management and Technology. 5(1):67-77

Putri, C.C., \& Nyoman, B.I. 2016. Pengaruh Desain Dan Kualitas Produk Terhadap Kepuasan Konsumen Melalui Kepuasan Pembelian Laptop Asus. Manajemen Dewantara. 1(1):110-122

Sugiyono. 2012. Metode Penelitian Bisnis. Cetakan Keenam Belas. CV Alfabeta.

Tangke, U. 2011. Analisis Kelayakan Usaha Perikanan Tangkap Menggunakan Alat
Tangkap Gill Net Dan Purse Seine Di Kecamatan Leihitu Kabupaten Maluku Tengah Provinsi Maluku. Agrikan: Jurnal Agribisnis Perikanan, 4(1):1-13

Suhdi, M. Analisis Penpapatan Dan Kelayakan Usaha Industri Tahu "Dani" di Kota Palu. Agroland: Jurnal IImu - ilmu Pertanian, 22(2):169-174

Sukmaningrum. A., \& Imron. A. 2017. Memanfaatkan Usia Produktif Dengan Usaha Kreatif Industri Pembuatan Kaos Pada Remaja Di Gresik. Paradigma. 05(03): 1-6

Tibrani., \& Sofyani, T. 2010. Pengorganisasian dan Analisis Usaha Perikanan Keramba di Waduk PLTA Koto Panjang Kabupaten Kampar. Jurnal Penelitian. 38(1):1-117

Wijaya, A.R., Huda, M.H., \& Manadiyanto. 2012. Penguasaan Aset Dan Struktur Pembiayaan Usaha Penangkapan Ikan Tuna Menurut Musim Yang Berbeda. Jurnal Sosek KP. 7(2):154-16

Yokasing, Y.B Pangalinan, A. \& da Luz, J.M. 2013. Upaya Memperbaiki Konstruksi Bubu Yang Digunakan Pada Perairan Bolok Kupang. Proton, 5(2):22-25 